Review Article

\title{
PROTON PUMP INHIBITORS AND THE RISK OF CHRONIC KIDNEY DISEASES: A CRITICAL REVIEW
}

SHAREEF J. ${ }^{1}$, SRIDHAR S. B. ${ }^{2}$, SHARIFF A. ${ }^{3}$

\author{
1,2,3Department of Clinical Pharmacy and Pharmacology, Ras Al Khaimah College of, Pharmaceutical Sciences, Ras Al Khaimah, United Arab \\ Emirates \\ Email: javedh@rakmhsu.ac.ae
}

Received: 13 Jun 2020, Revised and Accepted: 16 Aug 2020

\begin{abstract}
Proton pump inhibitors (PPIs) are most widely used medications for acid related gastrointestinal disorders. Accessible evidence based studies suggest that the increased use of PPI is linked to a greater risk of developing kidney diseases. This review aims to determine the association of kidney disease with the use of proton pump inhibitor with various study designs. PubMed, Scopus and Google Scholar databases as well as a reference list of relevant articles were systematically searched for studies by using the following search terms; 'proton pump inhibitors', 'acute kidney injury', 'chronic kidney disease' and 'end stage renal disease'. Both observational and randomized controlled trials (RCTs) exploring the association of PPI use with kidney disease were eligible for inclusion. A total of 8 articles, including 9 studies ( $n=794,349$ participants) were identified and included in the review. Majority of the studies showed a higher risk of kidney outcomes in patients taking PPIs, with effect higher of acute kidney injury (4-to 6-fold) compared with chronic kidney disease and end stage renal disease (1.5-to 2.5-fold). However, the studies suggest that the strength of evidence is weak and could not prove causation. The risk increased considerably with the use of high dose of PPIs and prolonged duration of exposure necessitates the monitoring of renal function. Exercising vigilance in PPI use and cessation of proton pump inhibitor when there is no clear indication may be a reasonable approach to reduce the population burden of kidney diseases.
\end{abstract}

Keywords: Acute Kidney Injury, Chronic Kidney Disease, Proton pump inhibitors

(c) 2020 The Authors. Published by Innovare Academic Sciences Pvt Ltd. This is an open access article under the CC BY license (http://creativecommons.org/licenses/by/4.0/) DOI: http://dx.doi.org/10.22159/ijcpr.2020v12i5.39783. Journal homepage: https://innovareacademics.in/journals/index.php/ijcpr

\section{INTRODUCTION}

Proton Pump Inhibitors (PPIs) are the mainstay for the prophylaxis and treatment of various acid related gastrointestinal disorders They act by decreasing the production of gastric acid through irreversible binding to the hydrogen/potassium ATPase enzyme present in the gastric parietal cells of the stomach [1]. Their use is likely higher than estimates due to increased availability as over the counter medications and often used off-label for extended periods of time. However, the increased use of PPIs for a longer period of time has led to increased concerns about the adverse drug reactions such as Clostridium difficile infections community acquired pneumonia, poor intestinal absorption of vitamins and minerals, bone fractures, dementia, hypomagnesemia and more recently the risk of kidney disease [2].

Accessible evidence based studies suggests that the use of PPI is linked to a greater risk of developing kidney disease, including a series of case reports of acute interstitial nephritis and subsequent observational studies of acute and chronic kidney diseases [3] Chronic Kidney Disease (CKD) is a rapidly growing public health concern that substantially increase the risk of morbidity, mortality and accounts for an excessive burden on healthcare expenditure Risk factors such as diabetes mellitus and hypertension could not fully explain the increased prevalence of CKD, suggesting that the other factors and drug induced causes may also contribute to the disease process. Identifying and preventing the iatrogenic risk factors such as medications including the polypharmacy may help to encourage rational use of medications and decrease the burden of CKD. It has been observed that CKD might develop gradually without being noted or due to the secondary effects of acute kidney injury and hypomagnesemia which has been independently associated with declining kidney function without full recovery [4-6].

This current review aims to assess the association between the kidney disease and the use of proton pump inhibitors by presenting the updated information and to determine whether the adverse effects instruct changes to the current practice.

\section{Methods}

A comprehensive literature searches of recently published articles during the period of January 2016 to October 2019 was undertaken by using the three electronic databases (PubMed, Scopus and Google Scholar). The following keywords such as Proton pump inhibitor and chronic kidney disease OR Proton pump inhibitor and chronic kidney failure OR Proton pump inhibitor and chronic renal failure OR Proton pump inhibitor and chronic renal disease OR Proton pump inhibitor and chronic renal insufficiency OR Proton pump inhibitor and end stage renal disease OR Proton pump inhibitor and end stage kidney disease were used to develop the search string. The studies were restricted to English publications. We also hand searched the reference lists of all included articles to find any additional appropriate eligible studies. The reviewers carefully screened titles and abstract independently, reviewed free full-text of articles for further assessment and inclusion and confirmed the final eligible records. Discrepancy between reviewers over inclusion of article were resolved by discussion or by consulting the third reviewer and attained consensus. A narrative review of the included studies was carried out.

\section{Inclusion criteria}

Eligible studies met the following criteria were included in the study: Study design consisting of clinical trials, cohort studies, casecontrol studies and case reports investigating the association of proton pump inhibitors with chronic kidney diseases.

\section{Exclusion criteria}

Review articles, editorials, letters, comments, abstracts, animal studies and meta-analysis were excluded.

\section{RESULTS}

We potentially retrieved 79 relevant articles through data base searches and 17 articles were remained for full text eligibility assessment after removing the duplicates and primary screening for titles and abstract. Finally, seven articles $(n=6,85,680$ participants) 
were found appropriate for inclusion after secondary screening with full text for analysis of the association between PPI use and the risk of chronic kidney diseases. Hand searching from the reference listed in the included articles did not find any additional article for inclusion. The flow chart of the selection of the studies for the review is shown in the fig. 1 .

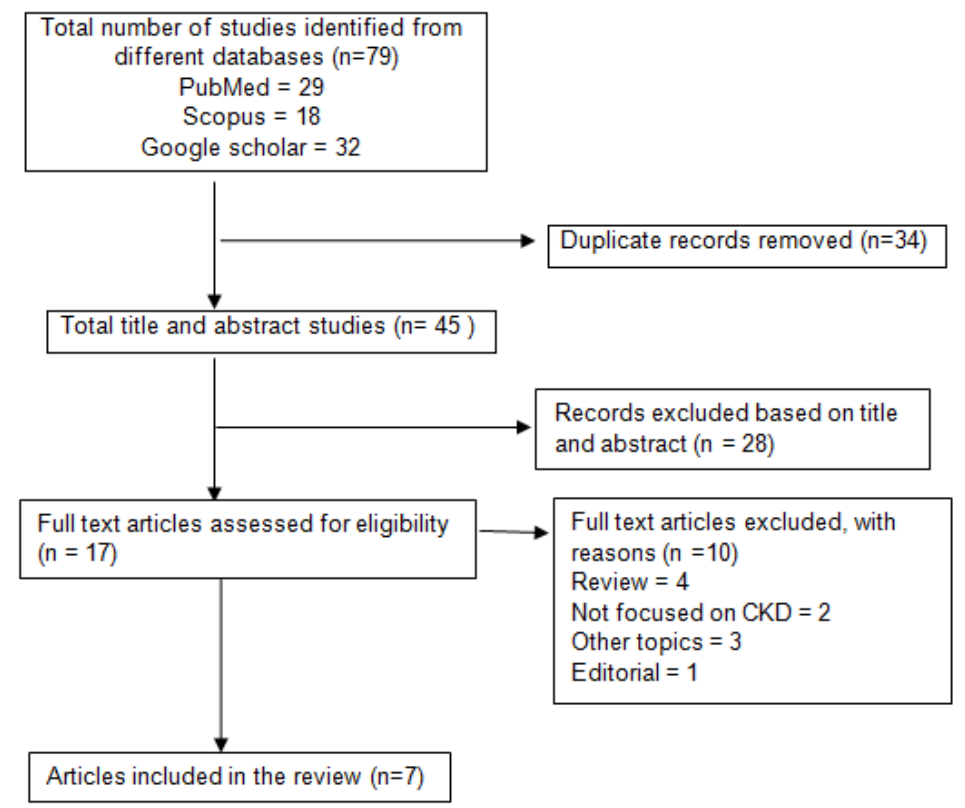

Fig. 1: Flow chart of selection of studies for review

Among the included studies, study conduct in the New York by Hart et al. [7] has included two cohorts in his article carrying out the risk assessment of acute kidney injury and chronic kidney diseases associated with PPI use. But our study criteria include patient with chronic kidney diseases and hence we have included only one cohort study. All the included articles were published from 206-2019. The main characteristics of the included studies assessing an association between PPI exposure and chronic kidney disease with their key findings are presented in the table 1.

Table 1: Studies evaluating for an association between PPI exposure and chronic kidney diseases and their findings

\begin{tabular}{|c|c|c|c|c|c|c|}
\hline S. No. & $\begin{array}{l}\text { Author, year of } \\
\text { study }\end{array}$ & Country & Study design & $\begin{array}{l}\text { Number of } \\
\text { participants }\end{array}$ & $\begin{array}{l}\text { Outcomes } \\
\text { assessed }\end{array}$ & Results \\
\hline 1 & $\begin{array}{l}\text { Hart et al., } 2019 \\
\text { [7] }\end{array}$ & USA & $\begin{array}{l}\text { Retrospective } \\
\text { Cohort study }\end{array}$ & $\begin{array}{l}1,77,935(93,335 \\
\text { patients in AKI } \\
\text { and } 84,600 \\
\text { patients in CKD) }\end{array}$ & $\begin{array}{l}\text { AKI and CKD } \\
\text { outcomes }(\mathrm{eGFR}<60 \\
\mathrm{ml} / \mathrm{min} / 1.73 \mathrm{~m}^{2} \text { and } \\
\text { ESRD })\end{array}$ & $\begin{array}{l}\text { PPI use associated with increased risk of } \\
\text { AKI (aOR 4.35, 95\% CI 3.14-6.04) and } \\
\text { CKD (aOR 1.20, 95\% CI 1.12-1.28) }\end{array}$ \\
\hline 2 & $\begin{array}{l}\text { Rodriguez- } \\
\text { Poncelas et al. } \\
2018[8]\end{array}$ & Spain & $\begin{array}{l}\text { Population- } \\
\text { based } \\
\text { cohort study }\end{array}$ & 46,541 & Incident of CKD & $\begin{array}{l}\text { Higher doses of PPIs increased the risk } \\
\text { of incident CKD (HR 1.92; 95\% CI 1.00- } \\
6.19 \text { ). }\end{array}$ \\
\hline 3 & Xie et al., 2017 [3] & USA & $\begin{array}{l}\text { Prospective } \\
\text { cohort study }\end{array}$ & 144,032 & Incidence of CKD & $\begin{array}{l}\text { The risk of CKD associated with PPI was } \\
1.28(1.22-1.34) \text { against non PPI use }\end{array}$ \\
\hline 4 & $\begin{array}{l}\text { Klatte et al., } 2017 \\
{[4]}\end{array}$ & Sweden & $\begin{array}{l}\text { Retrospective } \\
\text { cohort study }\end{array}$ & 114,883 & $\begin{array}{l}\text { Progression of CKD } \\
\text { (estimated by } \\
\text { doubling of } \\
\text { creatinine levels } \\
\text { and reduction in } \\
\text { glomerular } \\
\text { filtration rate }\end{array}$ & $\begin{array}{l}\text { PPI use associated with raised creatine } \\
\text { levels compared to HR receptor } \\
\text { antagonists ([HR], } 1.26 \text {; } 95 \% \mathrm{CI}, 1.05- \\
\text { 1.51)as well as reduction in the } \\
\text { estimated GFR by } 30 \% \text { or more ([HR] } \\
1.26 \text {; } 95 \% \mathrm{CI}, 1.16-1.36\end{array}$ \\
\hline 5 & Xie et al. 2016 [9] & USA & $\begin{array}{l}\text { Prospective } \\
\text { cohort study }\end{array}$ & 193,591 & $\begin{array}{l}\text { Incident CKD, CKD } \\
\text { progression and } \\
\text { ESRD. }\end{array}$ & $\begin{array}{l}\text { PPI users had an increased risk of } \\
\text { incident CKD (HR, } 1.28 ; 95 \% \mathrm{CI}, 1.23 \text { to } \\
\text { 1.34), doubling of serum creatinine level } \\
\text { (HR, } 1.53 ; 95 \% \text { CI, } 1.42 \text { to } 1.65 \text { ) and of } \\
\text { ESRD (HR, } 1.96 ; 95 \% \text { CI, } 1.21 \text { to } 3.18 \text { ) }\end{array}$ \\
\hline 6 & $\begin{array}{l}\text { Lazarus et al., } \\
2016[10]\end{array}$ & USA & $\begin{array}{l}\text { Population } \\
\text { based cohort } \\
\text { study }\end{array}$ & 10482 & Incidence of CKD & $\begin{array}{l}\text { Risk of CKD with PPI use was } 1.39 \text { (1.01- } \\
\text { 1.91) against no PPI use }\end{array}$ \\
\hline 7 & $\begin{array}{l}\text { Peng et al., } 2016 \\
{[11]}\end{array}$ & China & $\begin{array}{l}\text { Population } \\
\text { based case- } \\
\text { control study }\end{array}$ & 7616 & $\begin{array}{l}\text { Risk of End Stage } \\
\text { Renal Disease } \\
\text { (ESRD). }\end{array}$ & $\begin{array}{l}\text { Use of PPI was associated with higher } \\
\text { risk of ESRD }(\mathrm{OR}=1.88,95 \% \mathrm{CI}=1.71 \text { - } \\
2.06) \text {. }\end{array}$ \\
\hline
\end{tabular}


A retrospective two cohort study was conducted in New York in $1,77,935$ patients aged $18 \mathrm{y}$ and above to examine the association between PPI use and the risk of AKI and CKD in general population without evidence of kidney diseases. By using logistic regression models, the study reported the association of use of PPI with increased risk of AKI (Adjusted Odds Ratio (aOR) 4.35, 95\% CI 3.146.04) and CKD (aOR 1.20, 95\% CI 1.12-1.28). The study also highlighted that the participants were having comorbidities such as diabetes, hypertension, heart failure and cardiovascular diseases and were on concomitant medications which make them more susceptible of developing renal complications. But the study results supported by multiple sensitivity analyses showed exclusion of comorbidities and cofounding factors for developing renal complications that made these findings generalizable [7].

Another population based retrospective cohort study was carried out in Spain included 46541 participants aged $15 \mathrm{y}$ and above diagnosed with/without CKD aimed to provide evidence on the association between PPI use and the incidence of CKD and to iddentify if there is any relationship between dose and exposure time. Using Anderson-Gill model of multivariate survival analysis adjusted for different clinical variables, the study reported that PP use in the initial visit (Hazard Ratio (HR) 1.18; 95\% CI 1.04 \pm 1.51 ) and those who started to use in the follow up visit (HR 1.37; 95\% CI $1.25 \pm 1.50$ ) was associated with incident CKD as compared to nonPPI users. The study also highlighted that the risk of incident CKD

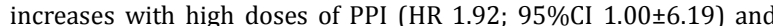
becomes apparent after three months of exposure (HR 2.40 ; $95 \% \mathrm{Cl}$ $1.65 \pm 3.46)$. Further-more, the study showed that the incident of CKD associated with PPI was not limited to one PPI but includes all different types of PPIs [8]

A retrospective cohort study was carried out in 1,44,032 patients of acid suppression therapy that included 1,25,596 PPI and 18,436 users of $\mathrm{H} 2$ receptor antagonists at Saint Louis Healthcare system in USA. The study was aimed to examine the association of PPI use with the risk of incident $\mathrm{CKD}$, the risk of CKD progression and the risk of ESRD in the absence of intervening acute kidney injury. The study reported that as the users of PPIs had an increased risk of CKD (hazard ratio 1.26; 95\% confidence interval 1.20-1.33), and ESRD $(1.30 ; 1.15-1.48)$ as compared with the users of $\mathrm{H} 2$ blockers. However, the findings that PPI use associated with adverse chronic renal outcomes in the absence of intervening AKI suggests that monitoring acute kidney injury (AKI) or acute interstitial nephritis among PPI users will not be sufficient sole mitigation strategy to guard against the development of CKD and ESRD [3]

Another study that reported a moderate in magnitude with the risk of CKD progression associated with the PPI use involving a total of $1,05,305$ new users of PPI therapy and 9578 new users of $\mathrm{H} 2$ receptor blockers constituting the study population was conducted in Sweden. It was a retrospective cohort study aimed to investigate the association between the PPI use and the risk of progression of CKD, defined as bifold increase in serum creatinine or decrease of $30 \%$ or more in estimated glomerular filtration rate. Using the adjusted Cox regression models, the study reported an increased risk of doubling the creatinine levels and decrease in estimated glomerular filtration rate of $30 \%$ or more in the users of PPI as compared with the users of $\mathrm{H} 2$ blockers. The study also observed risk of end stage renal disease and acute kidney injury associated with the PPI use but statistically non-significant. It is also important to highlight that the users of PPI in this study had comorbid conditions and were consuming other medication which might potentially contribute to risk of developing CKD outcomes as the study did not carry our sensitivity analysis to exclude the confounding factors [4]

Identical observations were also reported in two other studies [9, 10]. The first study was a primary cohort included users of PPI ( $\mathrm{n}=$ $173,321)$ and new users of H2blockers $(n=20,270)$ and followed for a period of $5 \mathrm{y}$ to ascertain renal outcomes. In adjusted Cox survival models, the study reported that the users of PPI had an increased risk of incident CKD (defined as doubling of serum creatinine or decrease in more than $30 \%$ of glomerular filtration rate) progression of CKD and ESRD. Furthermore, it was also detected a graded association between the risk of renal outcomes and duration of exposure of PPI among those exposed for more than $30 \mathrm{~d}$ as compared with $\leq 30 \mathrm{~d}$. The second study was Atherosclerosis Risk in Communities (ARIC) prospective cohort study of 10,482 participants followed for a median of $13.9 \mathrm{y}$. The study was aimed to quantify the association between PPI use and incident kidney disease in general population. After the $13 \mathrm{y}$ of follow up, users of PPI were associated with a $20-50 \%$ higher risk of developing incident CKD as compared to $\mathrm{H} 2$ antagonist's users and the risk was higher in twice daily as compared to the once daily dosing of PPI.

A case-control study was conducted in Taiwan to analyze the association between the use of proton pump inhibitors and the risk of ESRD among the patients with renal diseases. The study showed that PPI use was associated with significant higher risk of developing ESRD in patients with renal diseases Odds Ratio (OR) $1.88,95 \% \mathrm{CI}=1.71-2.06$ ). As compared to Non-End-Stage Renal Disease Group. Further-more the risk of developing ESRD associated with PPI was not limited to one but was extended to all individual PPIs [11]

\section{DISCUSSION}

The recent concerns of kidney diseases such as CKD and ESRD associated with the use of PPI has led to further investigations to assess these potential risks in patients receiving long term PPI therapy [12]. Even though the exact mechanism by which PPI induce kidney disease is unclear, several potential reasons might be explained by observed associations. One of the important factor that can probably explain the potential association is the development of acute interstitial nephritis in PPI users triggered by the immune mediated hypersensitivity reactions which is well documented. It has been reported that $30-70 \%$ of the patients who develop drug induced AIN have incomplete recovery of renal function leading to acute deterioration of kidney function and likely need of dialysis The most probable explanation is unrecognized/untreated or partially recovered AIN permitting the inflammatory tubulointerstitial process to progress over time to chronic irreversible interstitial fibrosis might develop CKD and progressing to ESRD [13-17]. Another potential possible mechanism by which PPI use can lead to CKD is through promoting hypomagnesemia causing endothelial cell dysfunction, oxidative stress and inflammation leading to renal interstitial tubular injury and decline in renal function. Further studies and more investigations are needed to gain a better understanding of this relationship and its mechanisms [18-20].

The evidence presented in this review are mainly observational studies and randomized controlled studies were not included. The strength of association along with the confounding factors and the potentiality for bias is also critical in attributing the causality associated with the use of PPI and the development of CKD considering the public health impact given the widespread extensive usage. The consistency of our findings with previous results on this topic ascertain that there is an association between PPI use and the development of CKD and ESRD. The risk ratio of developing CKD was approximately 1.1-1.9 fold higher among PPI users than H2RA users in both unadjusted and adjusted analyses for confounding variables. Higher risk was observed with the use of increased doses of PPIs and with prolonged durations of exposure to them and the increased likelihood of chronic renal outcomes can occur even in the absence of intervening AKI suggesting that monitoring for AKI or AIN among PPI users is not enough as sole mitigation strategy to safeguard against the development of CKD and ESRD. However, observational retrospective cohort studies and case-control study in this review associating PPI use with development of CKD shows that the strength of evidence or the graded association varies from weakmodest-strong may more likely to raise unnecessary concern among both users and prescribers and could not provide evidence for causation. In view of this findings, a more sensible and realistic approach is needed towards prescribing and better use of PPIs.

\section{CONCLUSION}

The current evidence related to the potential association of PPI use and CKD remains inconclusive in establishing causality. Until more 
data are available, careful monitoring of renal function while on PPIs may help in early identification and diagnosis of renal injury, withdrawing of the offending drug and further prevention of potentially life threatening kidney disorders. Exercising vigilance in PPI use and limiting to lowest effective dose for shortest possible time when considered and cessation in the absence of clear indication for use may be a reasonable approach to curtail the population burden of kidney diseases. Furthermore, prospective studies including randomized controlled trials should be carried out to confirm the findings of this review before drawing any conclusions.

\section{ACKNOWLEDGMENT}

We would like to express our gratitude to the President and Ras $\mathrm{Al}$ Khaimah Medical and Health Science University Research committee for giving permission to conduct the study. We are also very thankful to the Dean, Ras Al Khaimah college of Pharmaceutical sciences for providing necessary support and encouragement to the study.

\section{FUNDING}

$\mathrm{Nil}$

\section{AUTHORS CONTRIBUTIONS}

All the authors have contributed equally.

\section{CONFLICTING OF INTERESTS}

Declared none

\section{REFERENCES}

1. Yang Y, George KC, Shang WF, Zeng R, Ge SW, Xu G. Protonpump inhibitors use, and risk of acute kidney injury: a metaanalysis of observational studies. Drug Des Dev Ther 2017;11:1291-9.

2. Toth Manikowski S, Grams ME. Proton pump inhibitors and kidney disease-gi upset for the nephrologist? Kidney Int Rep 2017;2:297-301.

3. Xie Y, Bowe B, Li T, Xian H, Yan Y, Al-Aly Z. Long-term kidney outcomesamong users of proton pump inhibitors without intervening acute kidneyinjury. Kidney Int 2017;91:1482-94.

4. Klatte DCF, Gasparini A, Xu H, de Deco P, Trevisan M, Johansson ALV. Association between proton pump inhibitor use and risk of progression of chronic kidney disease. Gastroenterology 2017;153:702-10

5. Hussain S, Singh A, Habib A, Najmi AK. Proton pump inhibitors use and risk of chronic kidney disease: evidence-based metaanalysis of observational studies. Clin Epidemiol Global Health 2019;7:46-52.
6. Hung SC, Liao KF, Hung HC, Lin CL, Lai SW, Lee PC, et al. Using proton pump inhibitors correlates with an increased risk of chronic kidney disease: a nationwide database-derived casecontrolled study. Fam Pract 2018;35:166-71.

7. Hart E, Dunn TE, Feuerstein S, Jacobs DM. Proton pump inhibitors and risk of acute and chronic kidney disease: a retrospective cohort study. Pharmacotherapy 2019;39:443-53.

8. Rodriguez Poncelas A, Barcelo MA, Saez M, Coll-de-Tuero G. Duration and dosing of proton pump inhibitors associated with high incidence of chronic kidney disease in population-based cohort. PLoS One 2018;13:e0204231.

9. Xie Y, Bowe B, Li T, Xian H, Balasubramanian S, Al-Aly Z. Proton pump inhibitors and risk of incident $\mathrm{CKD}$ and progression to ESRD. J Am Soc Nephrol 2016;27:3153-63.

10. Lazarus B, Chen Y, Wilson FP. Proton pump inhibitor use and the risk of chronic kidney disease. JAMA Intern Med 2016;176:238-46.

11. Peng YC, Lin CL, Yeh HZ, Chang CS, Wu YL, Kao CH. Association between the use of proton pump inhibitors and the risk of ESRD in renal diseases: a population-based, case-control study. Medicine (Baltimore) 2016;95:e3363.

12. Nehra AK, Alexander JA, Loftus CG, Nehra V. Proton pump inhibitors: review of emerging concerns. Mayo Clin Proc 2018;93:240-6.

13. Moledina DG, Perazella MA. Proton pump inhibitors and CKD. J Am Soc Nephrol 2016;27:2926-8.

14. Wu B, Shang W, Li Y, Ren Y, Liu Z, Wei H, et al. Association between proton pump inhibitors use and kidney diseases: a meta-analysis. Int J Clin Exp Med 2018;11:6465-73.

15. Yang H, Juang SY, Liao KF. Proton pump inhibitors use and risk of chronic kidney disease in diabetic patients. Diabetes Res Clin Pract 2019;147:67-75.

16. Hedaiaty M, Tamadon MR, Amiri A, Mahmoodnia L. Protonpump inhibitors and risk of renal disease. J Nephropharmacol 2017;6:33-7.

17. Wyatt CM. Proton pump inhibitors and chronic kidney disease: is it time to sound the alarm? Kidney Int 2016;89:732-3.

18. Arora P, Gupta A, Golzy M. Proton pump inhibitors are associated with increased risk of development of chronic kidney disease. BMC Nephrol 2016;17:112.

19. Jaynes $M$, Kumar $A B$. The risks of long-term use of proton pump inhibitors: a critical review. Ther Adv Drug Saf 2018;10:1-13

20. Cheema E. Investigating the association of proton pump inhibitors with chronic kidney disease and its impact on clinical practice and future research: a review. J Pharm Policy Pract 2019;12:6. 